\title{
The effect of calcite and blast furnace slag on the rheology properties of self-compacting concrete in meso and macro scales
}

Murat Gökçe (Main Author, Corresponding Author)

Architecture Faculty, Architecture Department, Amasya University

05100, Amasya (Turkey)

muratgokce74@hotmail.com

Osman Şimşek

Faculty of Technology, Civil Engineering Department, Gazi University

06560, Ankara (Turkey)

simsek@gazi.edu.tr

Manuscript Code: 27717

Date of Acceptance/Reception: 16.03.2021/19.01.2021

DOI: 10.7764/RDLC.20.1.190

\begin{abstract}
In this study, the effects of blast furnace slag (BFS) and calcite on rheological properties of self-compacting concrete (SSC) in meso and macro scales were investigated. During the preparation of replicate samples, while BFS was replaced with the cement at the rate of $10 \%, 20 \%$, $30 \%$, and $40 \%$ by weight, calcite was added to the cement at the rate of $10 \%, 15 \%, 20 \%$, and $25 \%$ by weight. The rheological properties (plastic viscosity and yield point) and mini-slump flow values of the cement paste prepared in meso scales were determined. The fresh flow consistency of concrete prepared in macroscale was tested with L-box flowing test. As a result, upon evaluating the rheological parameters of the pastes according to the Bingham model, while the pastes with a plastic viscosity value close to $1 \mathrm{~Pa} \cdot \mathrm{s}( \pm 100 \mathrm{MPa} \cdot \mathrm{s}$ ) and a mini-slump flow rate higher than $200 \mathrm{~mm}$ were observed to be more resistant to segregation and form a homogeneous flow consistency, their L-box flowing rates were determined to be homogeneous and high. Ideal SSCs were made by adding $20 \%$ and $25 \%$ calcite to $30 \%$ BFS and $40 \%$ BFS replaced mixtures respectively in this study. It was also concluded that ideal SCC could be produced with paste mixtures having $1 \mathrm{~Pa} \cdot \mathrm{s}$ ( $\pm 100 \mathrm{MPa} \cdot \mathrm{s}$ ) viscosity and mini-slump flow diameter higher than $200 \mathrm{~mm}$. With the increase in calcite addition rates in SSCs, the passing rate for the $L$ box test has increased.
\end{abstract}

Keywords: self-compacting concrete, calcite, blast-furnace slag, plastic viscosity, meso and macro scale interaction, Bingham model.

Introduction

Concrete is the most significant construction material that has occupied large usage areas and is still extensively used within the construction industry. With each passing day, high-performance concrete types with high durability and strength are replacing normal-strength concrete types especially in constructions in which the materials are exposed to harsh environmental conditions (Türkmen, İ., 2003; Demir, et al., 2018a; Demir, et al., 2017; Demir, et al., 2018b; \& Demir et al., 2020). In our day, the applicability capacities of concrete types during their designing processes have become crucial. The timeframe spent from the production to the formwork processes of the designed concrete and its service life after it is cast is all taken into account. To that end, choosing optimal chemical additives becomes crucial for the production of applicable concrete.

The rapid development of the technology of chemical additives has given acceleration to the development of concrete technology. Producing concrete with desired properties has been possible as a result of developing optimal chemical additives. When powder materials constituting concrete are mixed with water and chemical additives, chemical reactions start forming. These initial nano and micro-scale interactions create a change in the performance of concrete on meso and macro scale by affecting its fresh and hardened features. The nano-micro scale interaction must be analyzed better in order to change and improve the macro scale properties of concrete (Gökçe, M., 2013; Sevim, et al., 2021; Güzelküçük, et al., 2020).

Characteristics of particles such as the potential force on their surface (zeta potential values), particle distribution, crystallization structure, chemical structure, and mineralogical structure should be analyzed on the nano-macro scale. In mesoscale, rheological analyses are performed to determine the interaction among the particles, their frictional force, and resistance to flow. On the macro scale, fresh and hardened concrete tests (consistency, workability, homogeneous molding, compressive strength, etc.) should be performed. It is produced with low water/cement ratios, SCC demonstrates high levels of segregation resistance and durability performances. It decreases the force applied on the formwork by providing high early strength and makes taking an early mold possible. It consolidates by throwing air void away and tamping without applying any vibration and segregation thanks to its fluid and self-compatibility without any vibration characteristics. The most effective building blocks in these superior features of SCC is chemical additives. 
These additives have started to be preferred in ready-mix concrete production besides prefabricated concrete production with increased usage areas thanks to their features such as being poured within the formwork without any need for vibration and reducing high amounts of water. SCC can be used in both the prefabricated concrete and readymix concrete industry. As distinct from the traditional ready-mix concrete, the rheological properties of cement pastes are very important in SCC designing (Gökçe, et al., 2010). SCC must contain more paste material than traditional concrete in terms of volume. This makes it possible for SCC to flow and consolidate with its weight by enabling frictions among the aggregates to decrease. Increasing only the amount of cement in order to elevate the granular material volume can also instigate problems regarding high contraction and hydration heat formation, besides increasing concrete costs.

Therefore, in order to increase the granular material volume, increasing the number of fine aggregates $(0-4 \mathrm{~mm})$ within the concrete and accordingly producing SCC with the optimal fine material amount $(0.125 \mathrm{~mm}$ undersize) may be more viable. Studies performed on the rheological properties of both cement pastes and concrete are of vital importance to improve the calculations of SCC mixes. Especially, studying and properly grasping the rheological properties of cement pastes in SCC designs $(0.125 \mathrm{~mm}$ undersize chalk granule, cement, water, and polycarboxylate-based superplasticizer mix) will be very beneficial in reaching the desired performance levels in SCC production (Kordts, et al., 2003).

One of the pozzolanic industrial wastes is granulated blast furnace slag. By using the mineral additive BFS in concrete instead of cement, the impact of cement on the environment will be reduced. Calcite, which is used as a mineral filling, is a mineral that is the building stone of limestone. Thanks to the concepts of rheology, it is possible to improve SCC and grasp its long-term performance levels better. Fresh mortar and concrete have been proven to demonstrate viscoplastic behaviors in the Equation (1) by Bingham, where $\tau(\mathrm{Pa}), \nu(1 / \mathrm{s})$ is shear stress in shear rate, $\tau 0$ is yield point, and $\mu$ is plastic viscosity (Yilmaz, R., 2007; Blombed, J., 1974; Caufin, et al., 1984).

$$
\tau=\tau_{0}+\mu \cdot \gamma
$$

When the shear stress is applied to a fluid, a constant deformation occurs in that fluid. This deformation rate is known as the shear rate $(\gamma)$, which is equal to the velocity gradient value of molecules. Viscosity $(\mu)$ is the inner friction characteristic of a fluid resulting from molecules of neighboring layers pulling each other during parallel layers' movement of sliding over one another. Viscosity is the resistance of a fluid against fluidity. The viscosity of water in $20^{\circ} \mathrm{C}$ temperature is acknowledged to be $1 \mathrm{cp}$ (Özkul, et al., 2002). In practice, shear stress ( $\tau$ ) occurs in fluids in the case of a movement. External effects such as pouring, spraying, or mixing form shear stress in fluids. If the shear stress $(\tau)$ applied to the fluid is directly proportional to the shear rate (the occurrence speed of deformation, $\gamma$ ), i.e., if the viscosity of the fluid does not change, this fluid is called a Newtonian fluid (Caufin, et al., 1984).

There is no proportional relation between shear stress and the occurrence speed of deformation in non-Newtonian fluids. Plastic-type (Bingham plastic) fluids have initial stress that needs to be applied for the fluid to start flowing, while also behaving as a pseudoplastic. The apparent viscosity levels of different fluids may be the same as each other; therefore, rheological properties must be measured in shear rates in real-life production conditions (Feys, et al., 2007a). When the Bingham model is applied to SCC, low, sometimes zero, and in some cases, even negative values of yield point may be obtained. Negative yield point values are physically impossible to occur. In order to avoid obtaining a negative yield point value, another nonlinear model should be applied to rheological data (Feys, et al., 2007b). The modified Bingham model can be used instead of the Bingham model in the case of negative yield point value occurrences (Khayat, et al., 1997).

\section{State of the art}

Feys et al. (2008) analyzed the rheological measurements of SCC. SCC types produced by adapting the Bingham model were determined to bear extremely low yield points, sometimes even zero or below zero. The modified Bingham model was suggested instead of the Bingham model in the case of yield points expressing negative values. In the literature (Anjuna, et al., 2016; Boukhelkhal, et al., 2015; Schwartzentruber, et al., 2006; Ezhilarasi, et al., 2020; Souza, et al., 2018; Mohammed, et al., 2016; Concha, et al., 2020; Gowda, et al., 2020; Hočevar, et al., 2013; Ling, et al., 2018; Petit, et al., 2007) the effects of some mineral and chemical additives on the rheological properties of SCCs have been investigated. Anguna and Nivin (2016) investigated the effect of metakaolin and silica fume on the rheological properties of SCCS where they are substituted for cement. It was concluded that the addition of mineral additives reduced the flowability and passing ability of the concrete but only increased the viscosity of the mixture.

Boukhelkhal et al. (2015) examined the effect of mineral additive types on the rheological properties of SCCs, it was stated that the use of limestone powder and slag increased the fluidity of the SCC mixture but negatively affected the stability. It was also concluded that the use of limestone powder and slag in SSCs increased the workability of fresh 
concrete up to 90 minutes and with this feature, it can be used in hot weather. Schwartzentruber et al. (2006) investigated the rheology properties of cement pastes for SCCs. Also, the correlation between macro-scale concrete mixtures and small-scale cement pastes was investigated. Ezhilarasi and Reya (2020) investigated SCC produced by using industrial waste materials. It was stated that when the silica fume was replaced at a rate of $15 \%$ instead of cement, an average increase of $22 \%$ in compressive, flexural, and splitting tensile strengths occurred. In addition, in a study about the rheology of concrete, it was reported that the slump-flow test and $L$ box test are simple and easy experiments showing the rheology of concrete (Souza, et al., 2018).

Mohammed et al. (2016) investigated the effect of nano-silica on the properties of the concrete. It has been determined that nano-silica adversely affects the workability of concrete but improves the compressive strength. Concha and Baccay (2020) examined the effect of mineral and chemical additives on the rheology of SCCs, with the increasing amount of air entrained additive and superplasticizer significantly increased the ability of concrete to resist transition, filling, and segregation. Gowda et al. (2020) investigated the development of SCCs using silica fume, SSCs were made by replacing cement with up to $15 \%$ silica fume. It has been reported that in SSCs produced with silica fume, the viscosity decreases but the compressive strength increases. Hočevar et al. (2013) analyzed the rheological properties of 26 different types of fresh concrete with two different types of rheometers. It was determined that there is a correlation between yield stress and plastic viscosity among the two rheometers used.

They also stated that there is a strong relationship between yield stress and workability and a weak relationship between workability and plastic viscosity. Ling et al. (2018) analyzed the rheological behavior of metakaolin and silica fume in SSCs. It was found that substituting metakaolin and silica fume instead of $4 \%, 6 \%$, and $8 \%$ fly ash (FA) decreased the viscosity of SCC. Furthermore, it is also reported that the total amount of metakaolin and silica fume should not exceed $6 \%$ in SCCs. Petit et al. (2007) have analyzed the relationship between yield stress and viscosity in mortar and SCC. The test results found that the yield stress and plastic viscosity of the mortar mixes changed linearly with the elapsed time, while an exponential variation of this rheological parameter was observed in SCC.

In this study, the rheological properties of the fresh paste in mesoscale, namely plastic viscosity and yield point, have been investigated. In addition, the performance levels of fresh concrete in the macro scale have been measured, and the effects of the mesoscale interaction on the macro scale process have been analyzed. In short, the relation between the analyses performed in meso and macro scale have been examined in depth in this study.

\section{Materials and methods}

In this study, the effects of different proportions of BFS and calcite on the rheological properties of self-compacting concrete were analyzed in meso and macro scales. During the preparation of replicate samples, BFS was replaced to mix instead of cement at the rate of $10 \%, 20 \%, 30 \%$, and $40 \%$ by weight respectively. Also, calcite was added to the mix instead of cement at the rate of $10 \%, 15 \%, 20 \%$, and $25 \%$ by weight respectively. In mesoscale, the rheological properties (plastic viscosity, yield point, and types of flow behavior) and mini-slump flow values of the pastes were determined. In the macro scale, the fresh consistency, consistency preservation, specific weight, and L-box test results of the prepared concrete types were calculated.

\section{Materials}

\section{Aggregates}

In the study, chalk-based crushed stones, with a maximum granule size of $22 \mathrm{~mm}$, were used as aggregates, whose physical properties are shown in Table 1. The grain distribution of the aggregates is given in Table 2.

Table 1. Physical properties of the aggregate. (Self-Elaboration).

\begin{tabular}{lccc}
\hline \multicolumn{1}{c}{ Physical properties } & Fine Aggregates & \multicolumn{2}{c}{ Coarse Aggregates } \\
\hline Sieve range & $0-4 \mathrm{~mm}$ & $4-12 \mathrm{~mm}$ & $12-22 \mathrm{~mm}$ \\
Density $\left(\mathrm{g} / \mathrm{cm}^{3}\right.$ ) & 2.60 & 2.63 & 2.65 \\
Water absorption values (\%) & 1.50 & 0.75 & 0.25 \\
\hline
\end{tabular}

Table 2. Aggregate sieve analysis. (Self-Elaboration).

\begin{tabular}{cccc}
\hline \multirow{2}{*}{$\begin{array}{c}\text { Sieve Size } \\
(\mathrm{mm})\end{array}$} & $0-4$ & $4-12$ & $12-22$ \\
\cline { 2 - 4 } & Passing \% & Passing \% & Passing \% \\
\hline
\end{tabular}




\begin{tabular}{cccc}
\hline 32 & 100 & 100 & 100 \\
22 & 100 & 100 & 73 \\
16 & 100 & 100 & 10 \\
8 & 100 & 93 & 2 \\
4 & 99 & 12 & 0 \\
2 & 83 & 1 & 0 \\
1 & 60 & 1 & 0 \\
0.5 & 33 & 1 & 0 \\
0.25 & 21 & 1 & 0 \\
0.125 & 9 & 0 & 0 \\
\hline
\end{tabular}

\section{Chemical admixture}

Polycarboxylate-based superplasticizer chemical admixture was used in SCC. The physical properties of the polycarboxylate-based superplasticizer chemical admixture used in the study are shown in Table 3.

\begin{tabular}{lc} 
Table 3. The physical properties of the chemical admixture. (Self-Elaboration) \\
\multicolumn{1}{c}{ Properties } & Polycarboxylate \\
\hline Density $\left(\mathrm{g} / \mathrm{cm}^{3}\right)$ & 1.06 \\
$\mathrm{pH}$ & 5.6 \\
Solid matter (\%) & 25 \\
\hline
\end{tabular}

\section{Blast-furnace slag}

The density of BFS is $3 \mathrm{~g} / \mathrm{cm}^{3}$ and its specific surface area is $3785 \mathrm{~cm}^{2} / \mathrm{g}$. The chemical analysis of BFS is shown in Table 4.

Table 4. The chemical analysis of BFS, calcite, and cement. (Self-Elaboration).

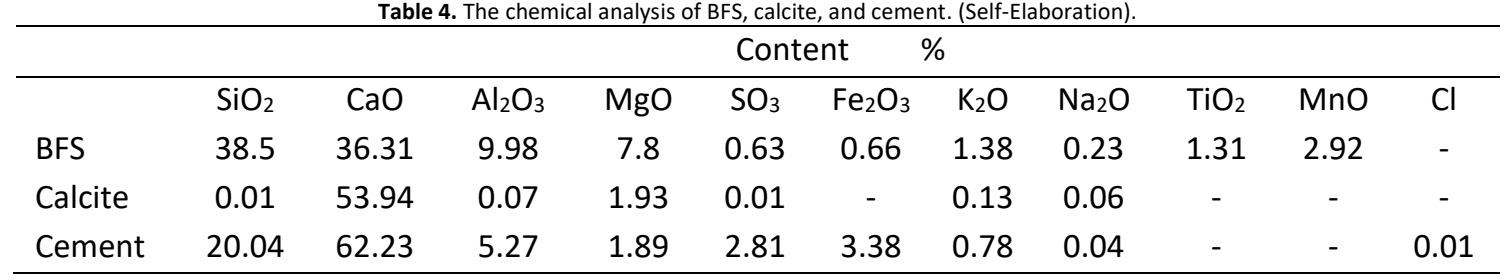

In the SEM analysis of BFS (Figure 1), smooth corner lines and smooth surface texture of large particles are seen, while smaller particles are seen to have irregular and rough surface texture.

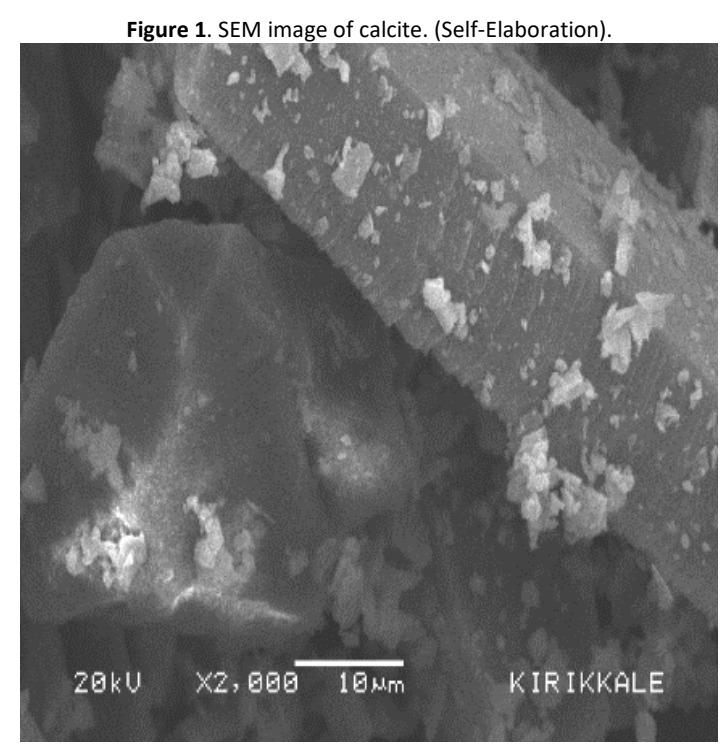




\section{Calcite}

Calcite used in the study was sifted through a $75 \mu \mathrm{m}$. sub sieve. The density of calcite corresponds to $2.72 \mathrm{~g} / \mathrm{cm}^{3}$ and its specific surface area is $4160 \mathrm{~cm}^{2} / \mathrm{g}$. The XRD (Figure 2) and chemical (Table 4) analyses of calcite were performed, as a result of which, the calcite type used within the scope of our study was determined to be $98 \%$ calcite.

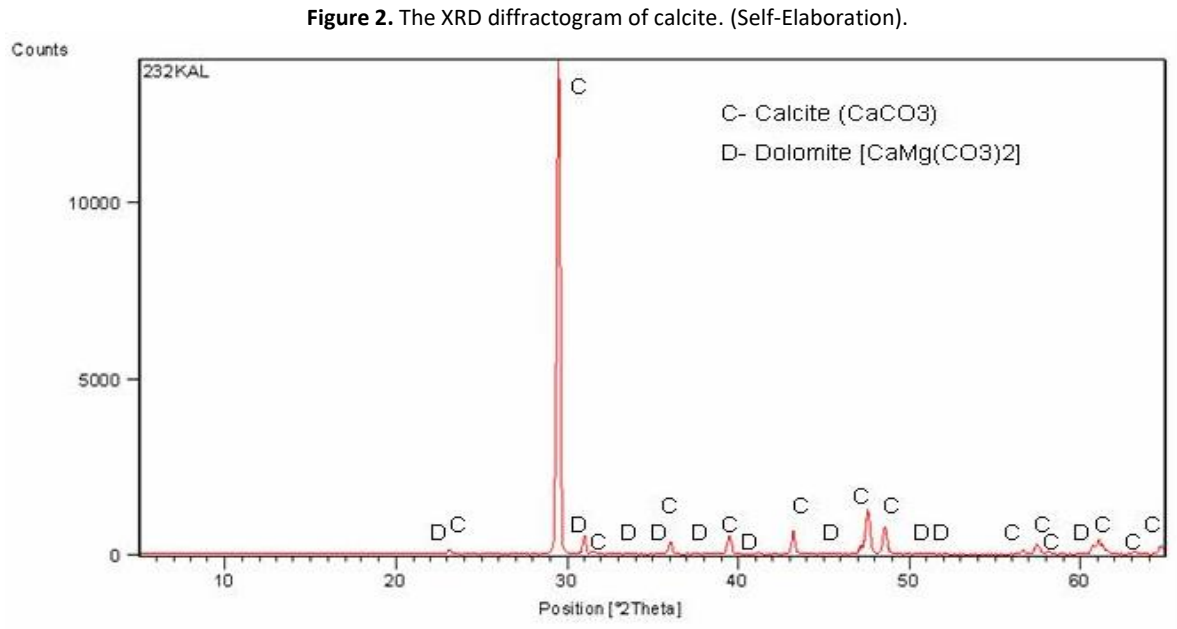

XRD analysis of powdered calcite was performed. In the study, XRD analysis of the samples was made using a Panalytical X'Pert Powder device with Cu X-Ray Tube. SEM analysis image of calcite is given in Figure 3. It is observed that calcite has more irregular geometric shapes compared to the BFS sample. Also, the surface texture of the calcite is rougher, and the grain size distribution has finer particles compared to the BFS sample.

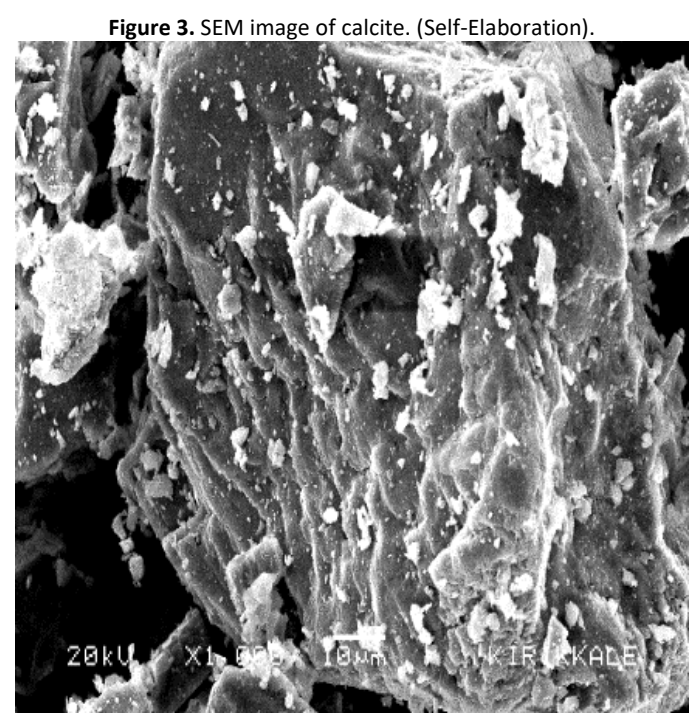

\section{Cement}

The type of cement used in the study was CEM I 42.5 R. The physical properties of cement are shown in Table 5 and the chemical analysis of cement is shown in Table 4.

Table 5. The physical properties of cement. (Self-Elaboration)

\begin{tabular}{|c|c|c|c|c|c|c|c|c|c|}
\hline $\begin{array}{l}\text { Physical } \\
\text { properties }\end{array}$ & $\begin{array}{l}\text { Density } \\
\left(\mathrm{g} / \mathrm{cm}^{3}\right)\end{array}$ & $\begin{array}{c}\text { 2-day } \\
\text { strength } \\
(\mathrm{MPa})\end{array}$ & $\begin{array}{c}\text { 7-day } \\
\text { strength } \\
\text { (MPa) }\end{array}$ & $\begin{array}{c}\text { 28-day } \\
\text { strength } \\
\text { (MPa) }\end{array}$ & $\begin{array}{l}\text { Initial set } \\
\text { (minutes) }\end{array}$ & $\begin{array}{c}\text { Final set } \\
\text { (minutes) }\end{array}$ & $\begin{array}{c}\text { Volume } \\
\text { expansion } \\
(\mathrm{mm})\end{array}$ & $\begin{array}{l}\text { Ignition } \\
\text { loss (\%) }\end{array}$ & $\begin{array}{c}\text { Insoluble } \\
\text { residue } \\
(\%)\end{array}$ \\
\hline & 3.1 & 27.3 & 40.8 & 51.7 & 162 & 282 & 1 & 2.5 & 0.44 \\
\hline
\end{tabular}




\section{Preparation of pastes and concrete}

The mix ratios of the pastes prepared for rheological measurements are given in Table 6 . The water/binder ratio was held constant as 0.33 in paste mix ratios. These mix ratios enabled the crucible used for rheological measurements to be filled. Moreover, the mini-slump flow values could be obtained without any segregation. When the water/binder ratio was changed to 0.50 in the concrete mixes, segregation problems occurred and reliable data could not be obtained. On the macro scale, concrete tests were performed. The cement dosage for the prepared concrete types was taken as $350 \mathrm{~kg} / \mathrm{m}^{3}$. BFS was replaced instead of cement at the rates of $10 \%, 20 \%, 30 \%$, and $40 \%$, and calcite was added to cement by $10 \%, 15 \%, 20 \%$, and $25 \%$ by weight. In every prepared concrete mix, the water/binder ratio was kept constant at the value of 0.50 . The effects of BFS and calcite additions on the consistency and workability of concrete were analyzed. The consistency (spread), consistency preservation, and L-box test results (the ability of concrete to flow through reinforcements) were obtained.

\begin{tabular}{|c|c|c|c|c|c|c|c|c|c|c|c|c|}
\hline \multirow{2}{*}{$\begin{array}{l}\text { Materials } \\
\text { Cement (g) }\end{array}$} & \multicolumn{12}{|c|}{ Amounts (g) } \\
\hline & \multicolumn{3}{|c|}{1000} & \multicolumn{3}{|c|}{1000} & \multicolumn{3}{|c|}{1000} & \multicolumn{3}{|c|}{1000} \\
\hline Water (g) & \multicolumn{3}{|c|}{330} & \multicolumn{3}{|c|}{330} & \multicolumn{3}{|c|}{330} & \multicolumn{3}{|c|}{330} \\
\hline $\begin{array}{l}\text { Calcite } \\
\text { (added by weight) }\end{array}$ & \multicolumn{3}{|c|}{$10 \%$} & \multicolumn{3}{|c|}{$15 \%$} & \multicolumn{3}{|c|}{$20 \%$} & \multicolumn{3}{|c|}{$25 \%$} \\
\hline BFS (\%) & 10 & 2030 & 40 & 10 & 20 & 40 & 10 & 20 & 40 & 10 & $20 \quad 30$ & 40 \\
\hline Admixture (g) & \multicolumn{3}{|c|}{10} & \multicolumn{3}{|c|}{10} & \multicolumn{6}{|c|}{10} \\
\hline
\end{tabular}

\section{Characterization methods for pastes and concrete}

In mesoscale, the rheological properties (plastic viscosity, yield point, and types of flow behavior) and mini-slump flow values of the pastes were measured. In the macro scale, the fresh consistency (spread), consistency preservation and Lbox test results of the produced concrete types were figured.

\section{Tests in meso scale}

In mesoscale, rheology and mini-slump flow tests were performed by using the prepared cement pastes. For the rheological measurements of the pastes, the Viskomat NT rheometer, which performs a two-point-type measurement, was used (Figure 4). Through this rheometer, torques $\mathrm{T}(\mathrm{N} \cdot \mathrm{mm})$ corresponding to different rotational speed values were measured. The gradient of the line, forming when torque and rotational speed $N(1 / \mathrm{s})$ data are graphed, gives viscosity $\mathrm{h}(\mathrm{N} \cdot \mathrm{mm} \cdot \mathrm{s})$, while the point on which the line in question cuts off the moment axis gives yield point $\mathrm{g}(\mathrm{N} \cdot \mathrm{mm})$. The rheological values were obtained by using the Bingham model (Equation 2).

$$
\boldsymbol{T}=\boldsymbol{g}+\boldsymbol{N} \cdot \boldsymbol{h}
$$

In the cases where negative yield point values were obtained, the Herschel-Buckley model (Equation 3) was utilized instead of the Bingham model.

$$
\tau=\tau_{0}+\mu \rho \gamma+C \gamma^{2}
$$

where,

$\tau=$ shear stress $(\mathrm{Pa})$,

$\tau 0=$ yield point $(\mathrm{Pa})$,

$\mu \mathrm{p}=$ plastic viscosity $(\mathrm{Pa} \cdot \mathrm{s})$,

$\nu=$ shear rate $(s-1)$ and $c=$ constant.

During the preparation process of the pastes, the mixing stage was performed according to EN 197-1 (2012). The velocity profile of the rheometer was arranged to $120,100,80,60$, and $40 \mathrm{rpm}$ (revolutions per minute) in order for every three minutes. Measurement results were obtained every 30 seconds, and the test lasted for 15 minutes. Torque-speed graphs were drawn based on the obtained measurement results. The torque values read in every rotational speed were graphed, and a line was drawn passing through the points closest to these values. The yield point and plastic viscosity values were figured from the point on which the line in question cut off the torque axis and the gradient of the line respectively. 


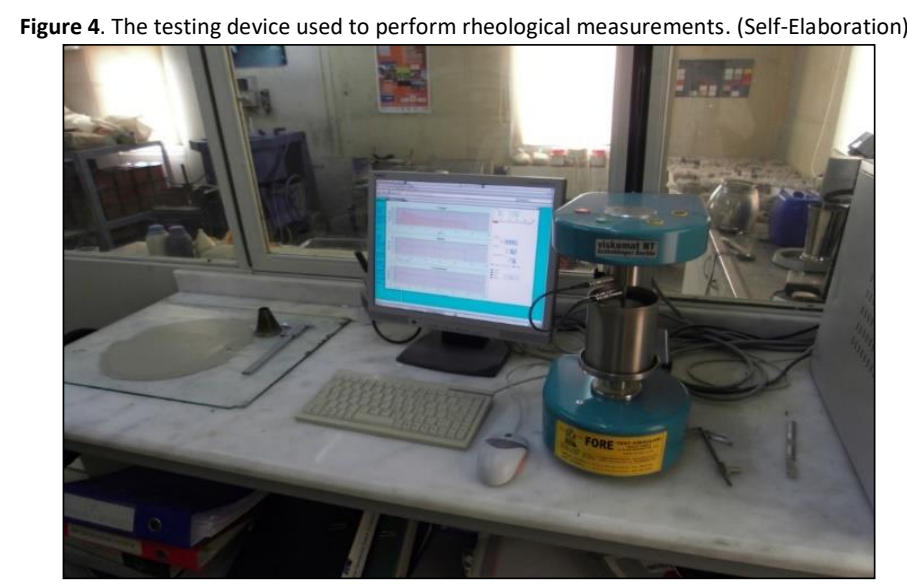

\section{Mini-slump flow test}

A simultaneous mini-slump flow test was applied to the pastes prepared for rheological tests. The consistency measurement of the cement paste was made according to EFNARC (2005). The diameter of the spread created by the cement paste was measured at two different points (Figures 5 and 6). The first measurement was made from the farthest corner of the spreading (D1). The second measurement was made from the farthest corner that cut this measurement line in the vertical direction (D2). The two measured lengths were averaged and recorded as the consistency result.
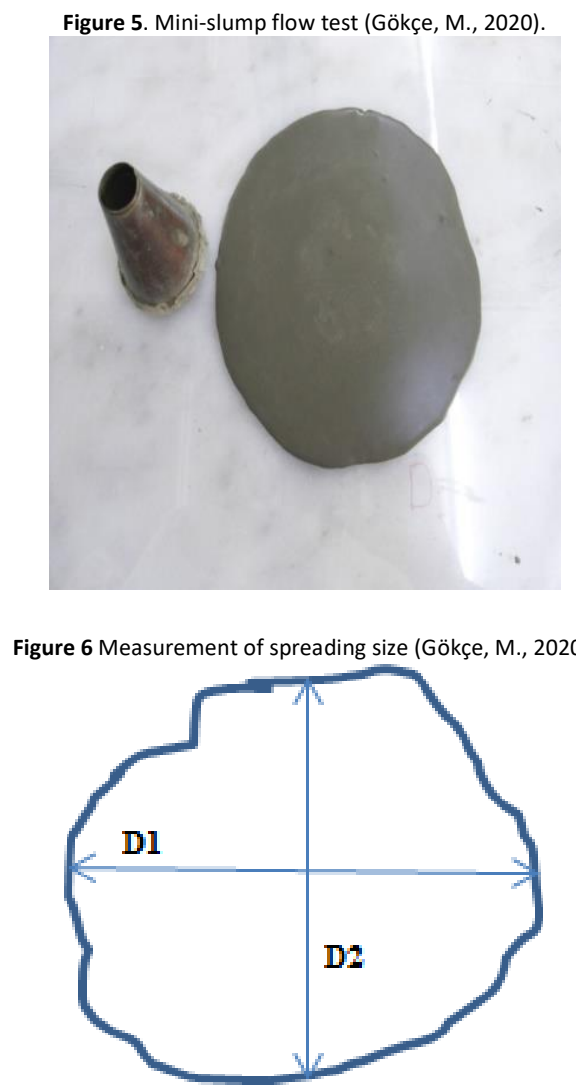

\section{Slump flow test}

The diameter of the fresh form of SCC by spreading with its own weight was measured using the spreading table according to EN 12350-8 (2019). Slump funnel (base diameter $200 \mathrm{~mm}$, upper diameter $130 \mathrm{~mm}$, height $200 \mathrm{~mm}$ ) and a table of $90 \times 90 \mathrm{~cm}$ were used as the test apparatus. The settling funnel was filled with SCC and expected to take its level with its own weight. The average diameter of the circularly spreading SCC was measured when the settling funnel was pulled at a constant speed and within a period of 5-10 seconds. The extent of the spread was calculated by taking the average of the distances measured from the farthest point of the concrete and the other endpoint perpendicular to this line. The classes of the spreading consistencies of concretes are given in Table 7. 


\begin{tabular}{lcccccc}
\hline \multicolumn{7}{c}{ Table 7. Flow classes $($ EN206, 2017). } \\
\hline Class & F1 & F2 & F3 & F4 & F5 & F6 \\
\hline Flow & $\leq 340$ & $350-410$ & $420-480$ & $490-550$ & $560-620$ & $\geq 630$ \\
Diameter $(\mathrm{mm})$ & & & & & & \\
\hline
\end{tabular}

Results and discussion

\section{Mesoscale results}

In mesoscale, the rheological measurements of the prepared pastes were performed. Plastic viscosity, yield point, and the type of flow behavior were found in the interaction between the granules in meso level. In addition, for the rheological measurements, the prepared pastes were subjected to a mini-slump flow test with the aid of a mini-slump cone. As can be seen in Figure 7 mini-slump flow values were observed to decrease as the rates of calcite addition to all the paste mix increased. As the addition rates of BFS increased, mini flow values became higher than the reference samples. While the addition of BFS increased the mini-flow diameters, the addition rates of calcite did the opposite.

The highest mini-flow diameter was determined to be $246 \mathrm{~mm}$, formed by the paste mix to which $60 \%$ cement, $40 \%$ BFS, and $10 \%$ calcite were added, while the lowest mini-flow diameter was measured to be $165 \mathrm{~mm}$ resulting from the paste to which reference $+25 \%$ calcite were added.

Figure 7. The mini-flow diameters of the pastes. (Self-Elaboration).

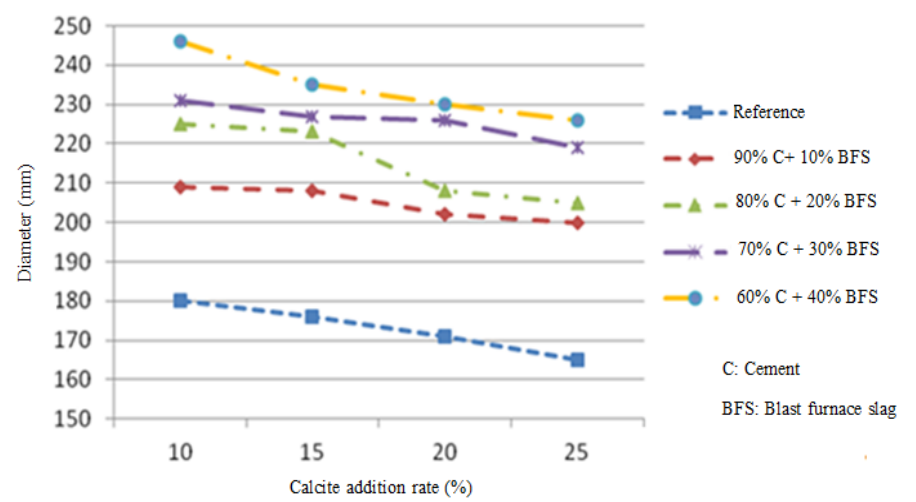

The rheological graphs of the pastes to which $60 \%$ cement, $40 \%$ BFS, and $10 \%, 15 \%, 20 \%$, and $25 \%$ calcite were added are given in Figure 8 and 9 . The increase in the addition rates of calcite elevated the torque and plastic viscosity values as can be seen in Figure 8 and 9 respectively. From the torque-speed graph, the yield point value was obtained from the point on which the line created based on the method of least squares cut off the $Y$-axis, and the plastic viscosity value was figured from the gradient of the line (Figure 8). Through the torque-time graph, the flow behavior of the paste depending on time was observed. The increase of torques over time demonstrated that there was an increase in the plastic viscosity values of the replicates and that their consistency and fluidity degraded over time. 


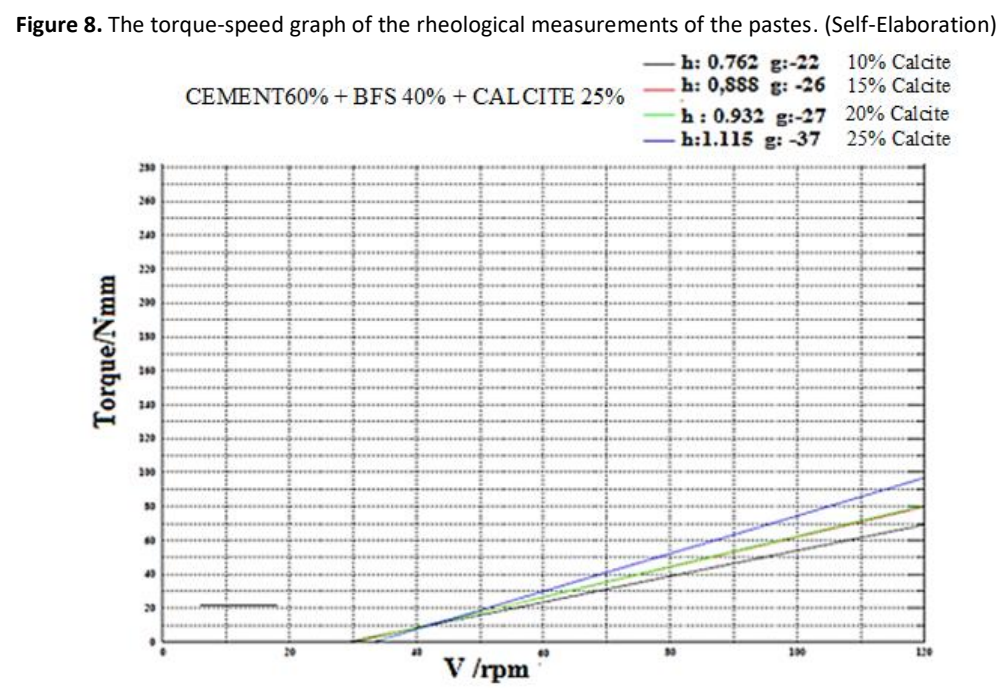

Figure 9. The torque-time graph of the rheological measurements of the pastes. (Self-Elaboration). CEMENT $60 \%+$ BFS $40 \%+$ CAL CITE $25 \%-60 \%$ C $+40 \%$ BFS $+10 \%$ Calcite $-60 \% \mathrm{C}+40 \% \mathrm{BFS}+15 \%$ Calcite $60 \% \mathrm{C}+40 \% \mathrm{BFS}+20 \%$ Calcite $-60 \% \mathrm{C}+40 \%$ BFS $+25 \%$ Calcite

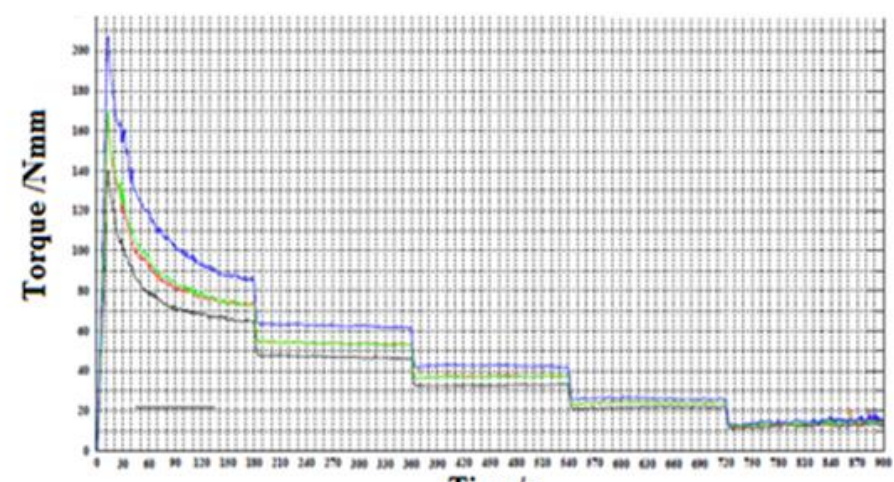

Time/s

The rheological values obtained according to the Bingham model are seen in Table 8. Adding calcite to the paste samples was determined to increase the plastic viscosity values. The highest plastic viscosity value was found to be $1.141 \mathrm{~Pa} \cdot \mathrm{s}$ in the paste mix made of $70 \%$ cement, $30 \%$ BFS, and $25 \%$ calcite, while the lowest plastic viscosity value was calculated as $0.628 \mathrm{~Pa} \cdot \mathrm{s}$ in the replicate paste to which $10 \%$ calcite was added. Increased BFS replacement rates led to similarly increased mini-flow rates.

The highest mini-slump flow diameter was determined to be $246 \mathrm{~mm}$ in the paste mix of $60 \%$ cement, $40 \%$ BFS, and $10 \%$ calcite, while the lowest one was found to be $165 \mathrm{~mm}$ in the replicate paste to which $25 \%$ calcite was added. Rheological properties may vary according to the water/cement ratio, cement type, the specific surface area of cement, mixing procedures, the amount of time spent after the mixing process, and temperature. The Bingham model is acknowledged to be a model representing viscoplastic behavior.

Table 8. The rheological results of the pastes according to the Bingham model. (Self-Elaboration).

\begin{tabular}{lccc}
\multicolumn{4}{c}{ Table 8. The rheological results of the pastes according to the Bingham model. (Self-Elaboration). } \\
\hline Granular paste & $\begin{array}{c}\text { Plastic } \\
\text { Viscosity } \\
\text { (Pa.s) }\end{array}$ & $\begin{array}{c}\text { Yield Point } \\
\text { (N.mm) }\end{array}$ & $\begin{array}{c}\text { Mini-flow } \\
\text { (mm) }\end{array}$ \\
\hline $100 \%$ Cement & 0.635 & -16 & 202 \\
$100 \%$ Cement +10\% Calcite & 0.628 & -10 & 180 \\
$100 \%$ Cement+15\% Calcite & 0.708 & -12 & 176 \\
$100 \%$ Cement+20\% Calcite & 0.799 & -18 & 171 \\
$100 \%$ Cement+25\% Calcite & 0.932 & -23 & 165 \\
$90 \%$ Cement+10\% BFS+10\% Calcite & 0.771 & -22 & 209
\end{tabular}




\begin{tabular}{llll}
$90 \%$ Cement+10\% BFS +15\% Calcite & 0.820 & -23 & 208 \\
$90 \%$ Cement+10\% BFS +20\% Calcite & 0.778 & -20 & 202 \\
$90 \%$ Cement+10\% BFS +25\% Calcite & 0.942 & -26 & 200 \\
$80 \%$ Cement+20\% BFS +10\% Calcite & 0.695 & -18 & 225 \\
$80 \%$ Cement+20\% BFS +15\% Calcite & 0.705 & -18 & 223 \\
$80 \%$ Cement+20\% BFS +20\% Calcite & 0.826 & -20 & 208 \\
$80 \%$ Cement+20\% BFS +25\% Calcite & 0.822 & -21 & 205 \\
$70 \%$ Cement+30\% BFS +10\% Calcite & 0.894 & -29 & 231 \\
$70 \%$ Cement+30\% BFS +15\% Calcite & 1.050 & -36 & 227 \\
$70 \%$ Cement+30\% BFS +20\% Calcite & 1.082 & -37 & 226 \\
$70 \%$ Cement+30\% BFS +25\% Calcite & 1.141 & -38 & 219 \\
$60 \%$ Cement+40\% BFS +10\% Calcite & 0.762 & -22 & 246 \\
$60 \%$ Cement+40\% BFS +15\% Calcite & 0.888 & -26 & 235 \\
$60 \%$ Cement+40\% BFS +20\% Calcite & 0.902 & -27 & 230 \\
$60 \%$ Cement+40\% BFS +25\% Calcite & 1.115 & -37 & 226 \\
\hline
\end{tabular}

When Bingham model was applied to determine the rheological parameters of the pastes, the yield point results were found to be negative, as a result of which the Herschel-Buckley model was used for the rheological results of the pastes and their yield point values were accordingly obtained. However, some of the yield point values obtained through the Herschel-Buckley model turned out to be negative as well due to the model acceptance (Table 9).

Table 9. The rheological results of the pastes according to Herschel-Buckley model. (Self-Elaboration).

\begin{tabular}{|c|c|c|}
\hline Fine Material Paste & $\begin{array}{l}\text { Yield Point } \\
(\mathrm{N} \cdot \mathrm{mm})\end{array}$ & $\begin{array}{c}\text { Plastic Viscosity } \\
\text { (Pa.s) }\end{array}$ \\
\hline $100 \%$ Cement & 4.85 & 0.132 \\
\hline 100\% Cement $+10 \%$ Calcite & -19.5 & 0.952 \\
\hline 100\% Cement $+15 \%$ Calcite & 2.75 & 0.312 \\
\hline 100\% Cement $+20 \%$ Calcite & -0.1 & 0.405 \\
\hline $100 \%$ Cement $+25 \%$ Calcite & 4.95 & 0.227 \\
\hline $90 \%$ Cement + 10\% BFS + 10\% Calcite & 7.8 & -0.015 \\
\hline $90 \%$ Cement + 10\% BFS + 15\% Calcite & 9.85 & -0.067 \\
\hline $90 \%$ Cement $+10 \%$ BFS + 20\% Calcite & 2.75 & 0.137 \\
\hline $90 \%$ Cement $+10 \%$ BFS + 25\% Calcite & 6.85 & 0.157 \\
\hline $80 \%$ Cement $+20 \%$ BFS $+10 \%$ Calcite & 1.8 & 0.16 \\
\hline $80 \%$ Cement $+20 \%$ BFS $+15 \%$ Calcite & -2.2 & 0.335 \\
\hline $80 \%$ Cement $+20 \%$ BFS $+20 \%$ Calcite & 5.65 & 0.167 \\
\hline $80 \%$ Cement $+20 \%$ BFS $+25 \%$ Calcite & 6.9 & 0.105 \\
\hline 70\% Cement $+30 \%$ BFS $+10 \%$ Calcite & 0.8 & 0.085 \\
\hline 70\% Cement + 30\% BFS + 15\% Calcite & -3.05 & 0.227 \\
\hline 70\% Cement $+30 \%$ BFS + 20\% Calcite & 3.05 & 0.72 \\
\hline $70 \%$ Cement + 30\% BFS + 25\% Calcite & 3.8 & 0.06 \\
\hline $60 \%$ Cement $+40 \%$ BFS $+10 \%$ Calcite & 13.95 & -0.222 \\
\hline $60 \%$ Cement $+40 \%$ BFS $+15 \%$ Calcite & -11.75 & 0.587 \\
\hline $60 \%$ Cement $+40 \%$ BFS $+20 \%$ Calcite & -11.75 & 0.587 \\
\hline $60 \%$ Cement $+40 \%$ BFS $+25 \%$ Calcite & -2.25 & 0.212 \\
\hline
\end{tabular}


The plastic viscosity results of the prepared pastes obtained from the Bingham model are seen in Figure 10. Increased calcite addition rates in the paste mixes were determined to provide a parallel increase in the plastic viscosity values. In the paste mix made of $70 \%$ cement, $30 \%$ BFS, and $25 \%$ calcite, the plastic viscosity value was found to be $1.141 \mathrm{~Pa} \cdot \mathrm{s}$. The lowest plastic viscosity value was calculated to be $0.628 \mathrm{~Pa} \cdot \mathrm{s}$ in the paste to which $100 \%$ cement and $10 \%$ calcite were added. BFS addition rates increased the plastic viscosity values depending on the replicate samples. Increases or decreases in the mini-slump flow values affected the plastic viscosity values, and consequently, a relation between minislump flow values and plastic viscosity was determined to exist.

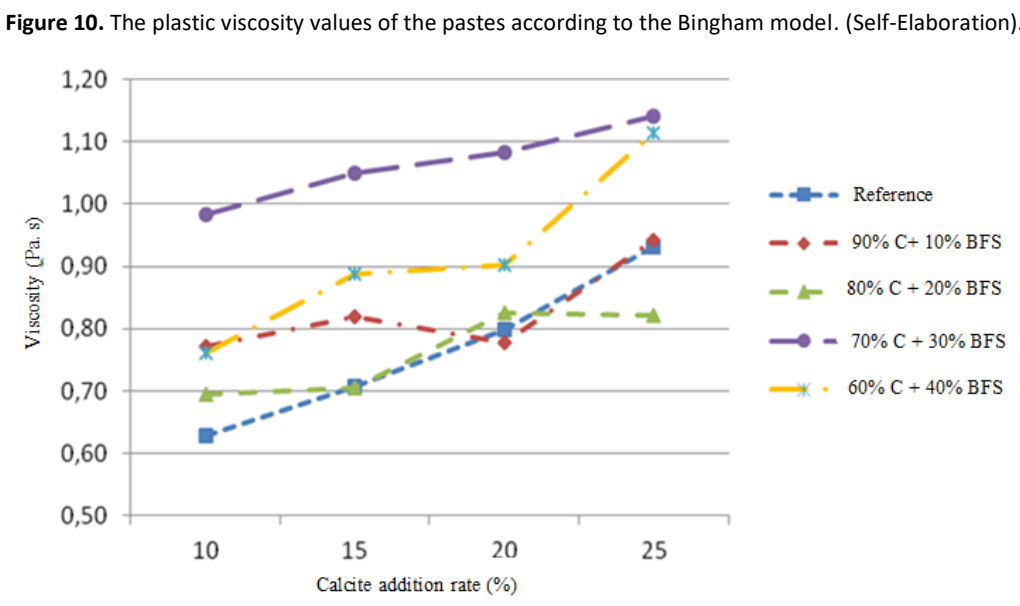

The decrease in mini-slump flow values resulted from the increase of friction between particles. The addition of calcite to the mixture increased the friction between the particles. In cement paste, as a result of the increase in the friction force between the particles, resistance to flow has occurred. Therefore, plastic viscosity increased as a result of the increase in resistance to flow. As the BFS ratio increased, the plastic viscosity decreased and the mini-slump values increased. BFS has been added to the mixes as a substitute for cement. Since cement reacts with water and the water requirement of cement is higher than BFS, the consistency of cement paste increased as the BFS ratio increased and showed more fluid properties. The plastic viscosity of cement paste with increased fluidity decreased.

\section{Macro scale results}

The effects of BFS and calcite additions on the consistency and workability of concrete were analyzed. The consistency (spread), consistency preservation and L-box test results (the ability of concrete to flow through reinforcements) were obtained. Figure 11 shows the passing ability of SCC (PA = H2/H1). Increased calcite rates were determined to have an effect on the increase in the flow rates. Because the calcite additions increased the number of granule materials within the concrete, they enabled the concrete types to be transported, penetrate through reinforcements, and homogeneously consolidate within the formwork easily. The highest flow rate was calculated to be 0.85 by the paste mix made of $60 \%$ cement, $40 \%$ BFS, and $25 \%$ calcite, while the lowest, 0.70 , belonged to the concrete type to which $60 \%$ cement and $40 \%$ BFS were added $0 \%$ content of calcite.

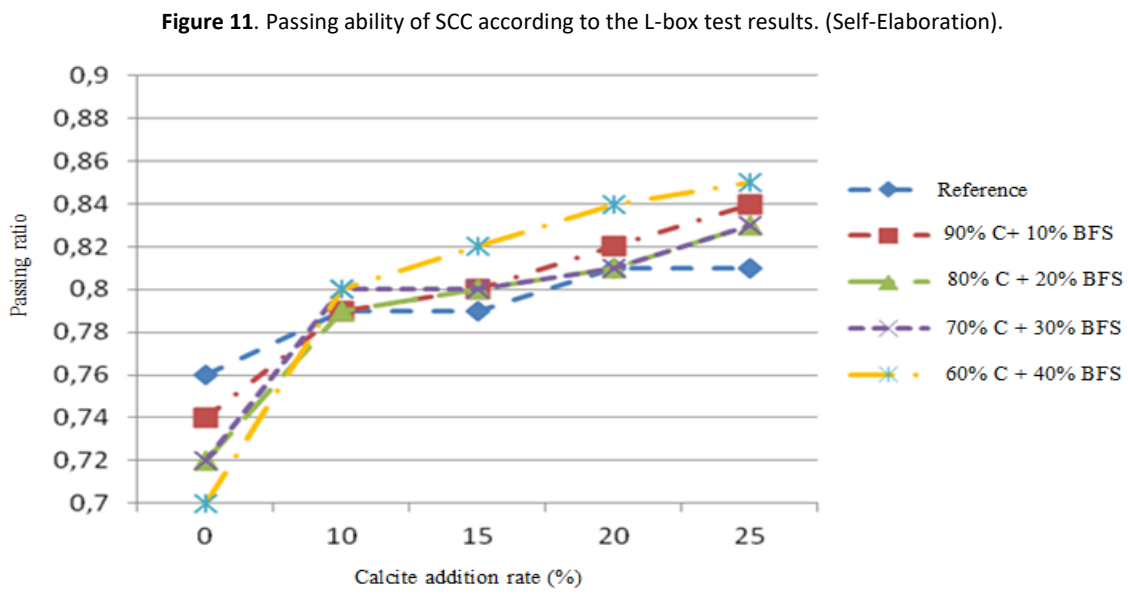

Figure 12 shows the $L$ box instrument used in the experiments. According to the $L$ box test results, the addition of calcite increased the passing rate of SSCs. In general, if the $L$ box ratio is greater than 0.80 , concrete is considered to have self- 
settling properties. In this study, it was determined that when the ratio of calcite addition to SSCs was 20 and $25 \%$, and the $L$ box passing ratio of all concretes was higher than 0.80 . In addition, with the increasing calcite addition rate, the passing rate of all concrete for the $L$ box test increased. If the passing ability is lower than 0.80 in SCCs, it will be difficult to pass through the reinforcement and the settlement capability will decrease. In SCCs, ideal concrete can be made as a result of the passage ability greater than 0.80 and at the same time being resistant to segregation.

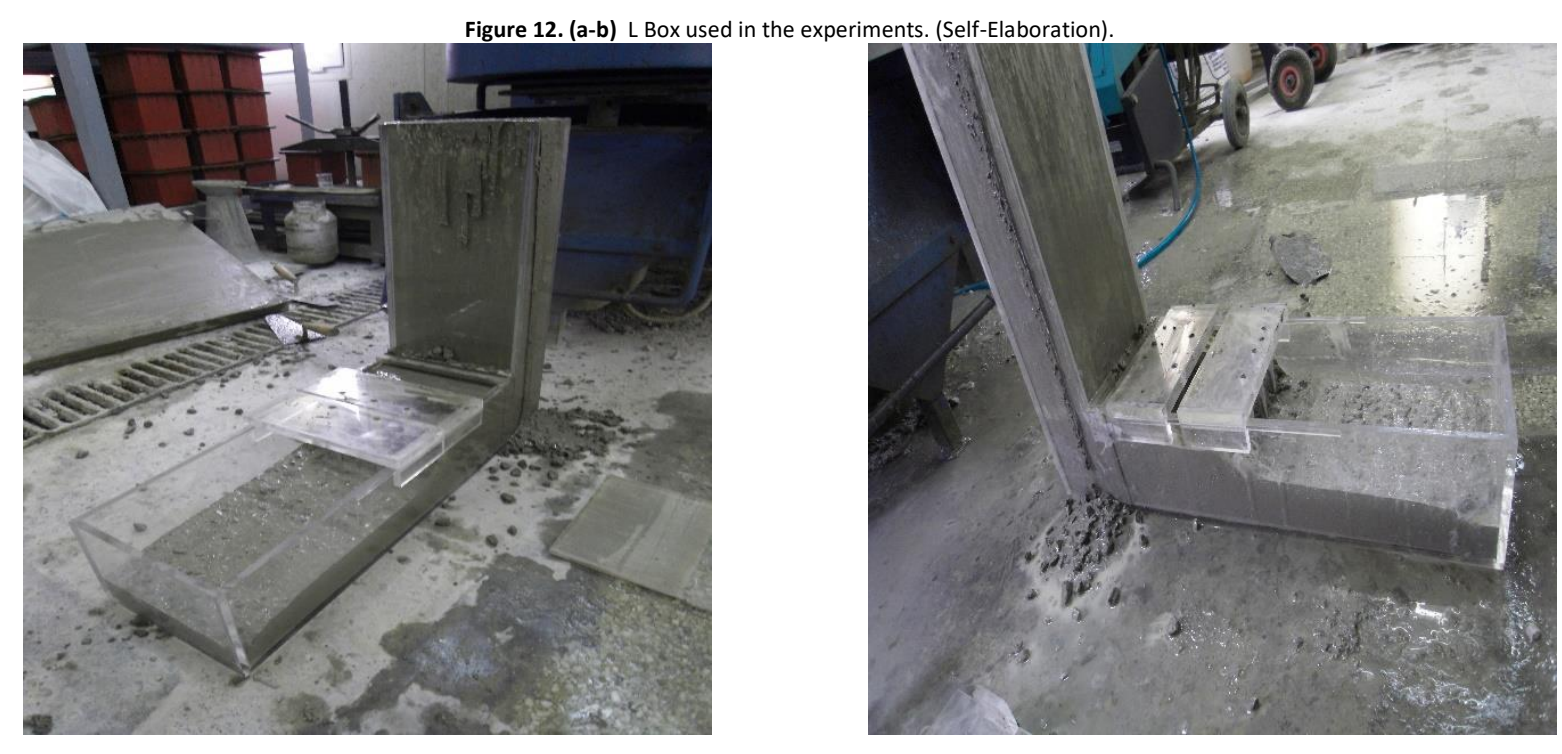

As can be seen in Figure 13, increased calcite addition rates were determined to result in decreased flow diameters, while the BFS replacement rates did the opposite.

Figure 13. The flow diameters of fresh SCC. (Self-Elaboration).

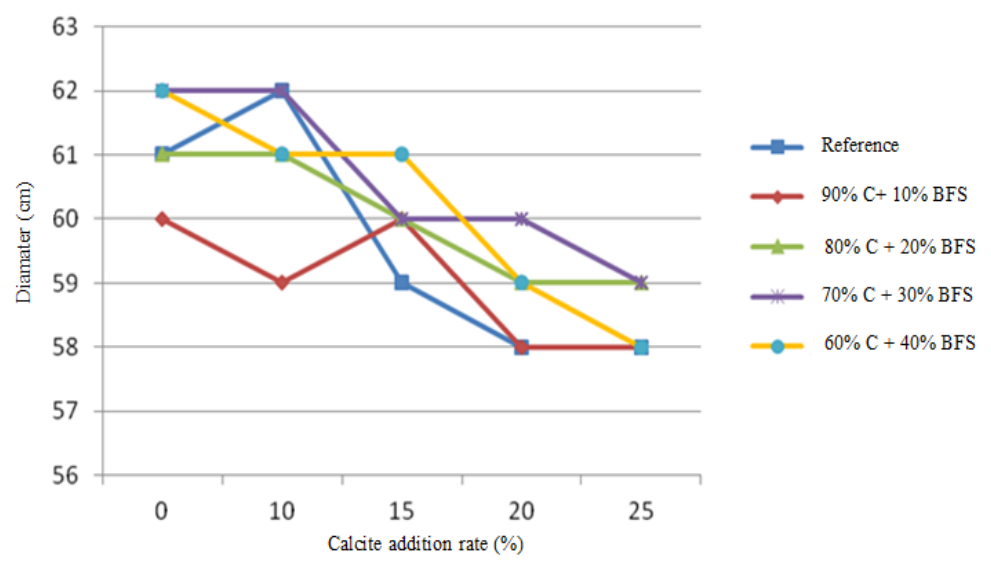

The flow consistency measurement results of SCC performed 30 minutes later, are seen in Figure 14 . Increased BFS replacement rates caused increased flow consistency diameters in SCC, while decreases in flow consistency diameters in SCC were observed to be caused by increased calcite addition rates. 
Figure 14. The flow diameters of fresh SCC. (Self-Elaboration).

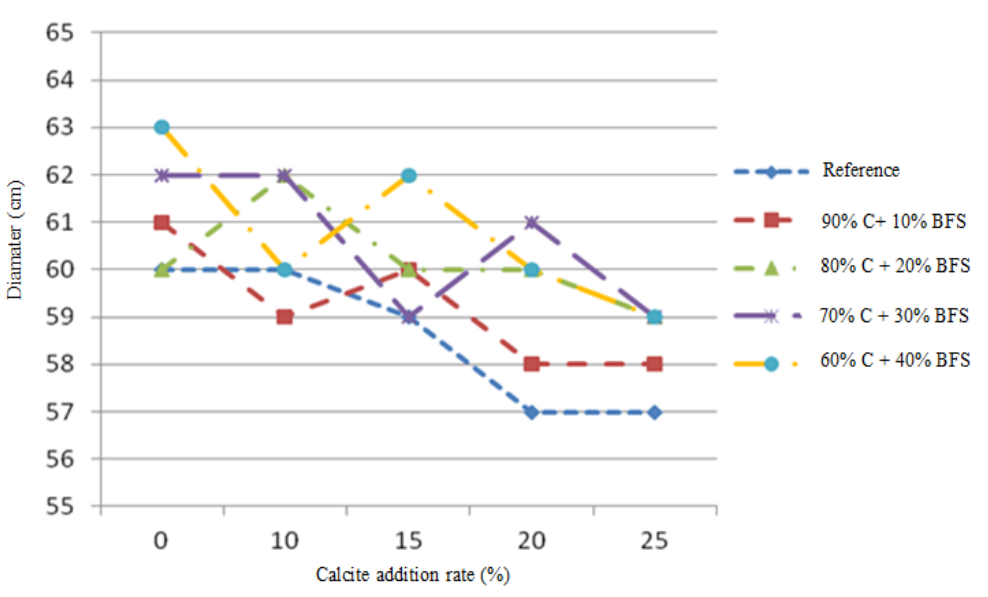

Figure 15. Spread measurement of SCCs (Gökçe, M., 2013).

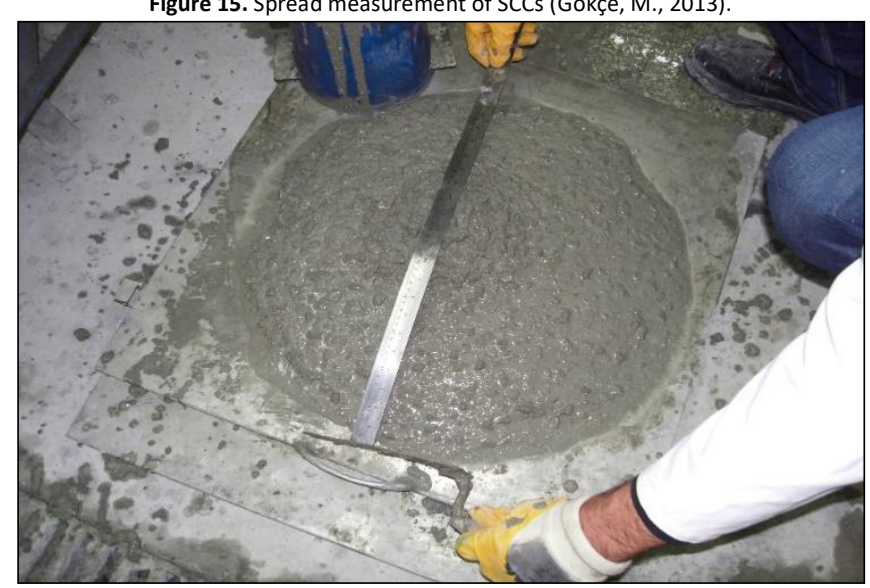

Figure 15 shows the Slump-flow test of SCCs. Spreading diameters and passing ratios of L box for SCCs are given in Figure 16. With increasing calcite addition rates in SSCs, the spreading diameter of the concrete decreased. However, the increase in calcite addition rates increased the passing ratios of L box in SSCs (Demir, et al., 2018c; Akgüngör, et al., 2018). With the increase in calcite addition rates, the amount of fine material $(>100 \mu \mathrm{m})$ increased in SSCs. With the increase in the amount of fine material in concrete, the coarse-grained aggregates (4-12 $\mathrm{mm}$ and $12-22 \mathrm{~mm}$ aggregates) were surrounded with more fine material. As a result of the coarse aggregates were surrounded with more fine material, it was easy to transport and move.

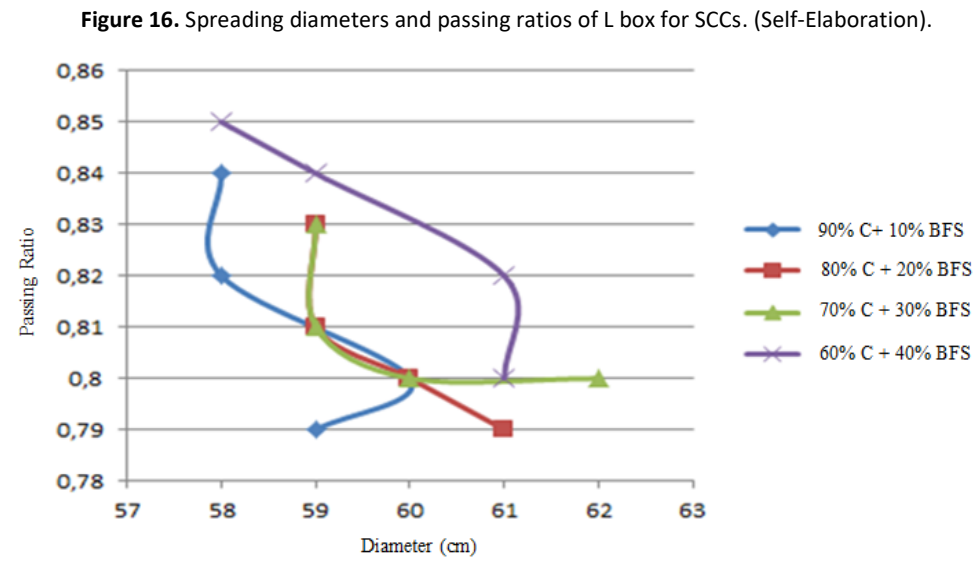

The performed meso and macro-scale analyses of SCC were examined in detail in this study. In consequence of results obtained from meso and macro scale tests, a strong relationship was acknowledged to exist in meso and macro scale for the mix ratio designs of SCC. Studies performed in meso scales have been acknowledged to pave the way for studies 
to be performed at macro scales. Rheological values must be determined in order to improve SCC and create an optimal SCC design by grasping its long-term performance better. The Bingham model is acknowledged to be a model representing the behavior of pastes. But in the cases where negative (-) yield point values were obtained, the HerschelBuckley model was adapted and new yield point values were obtained. However, the yield points obtained through this model bore inconsistent results as well.

The highest plastic viscosity value was found to be $1.141 \mathrm{~Pa} \cdot \mathrm{s}$ in the paste mix made of $70 \%$ cement, $30 \%$ BFS, and $25 \%$ calcite, while the lowest plastic viscosity value was calculated as $0.628 \mathrm{~Pa} \cdot \mathrm{s}$ in the replicate paste to which $10 \%$ calcite was added. Increased calcite addition rates led to increased plastic viscosity rates. Upon assessing the plastic viscosity results of the pastes obtained based on the Bingham model, the pastes with a close plastic viscosity value to $1 \mathrm{~Pa} \cdot \mathrm{s}( \pm 100$ $\mathrm{mPa} \cdot \mathrm{s})$ were determined to have relatively more resistance against segregation. Nevertheless, while plastic viscosity does increase the resistance against segregation, the capabilities of homogeneous flow and penetration through reinforcements must be high as well.

To that end, a homogeneous and increased flow consistency should be provided besides high plastic viscosity values. In this regard, while the paste mixes with $1 \mathrm{~Pa} \cdot \mathrm{s}( \pm 100 \mathrm{mPa} \cdot \mathrm{s})$ viscosity and mini-slump flow consistency higher than 200 $\mathrm{mm}$ were observed to be more resistant to segregation and form homogeneous flow consistencies, their L-box flow rates were also observed to be high and homogeneous. Arranging the number of granule materials with the paste mixes having $1 \mathrm{~Pa} \cdot \mathrm{s}( \pm 100 \mathrm{mPa} \cdot \mathrm{s})$ viscosity and mini-slump flow consistency higher than $200 \mathrm{~mm}$ will make it possible to produce ideal SCC.

Increased calcite addition rates were observed to cause increased capabilities of penetrating through reinforcements. The highest flow rate was calculated to be 0.85 by the paste mix made of $60 \%$ cement, $40 \%$ BFS, and $25 \%$ calcite, while the lowest, 0.70 , belonged to the concrete type to which $60 \%$ cement and $40 \%$ BFS were added. The number of granule materials within SCC increased with calcite additions, and aggregates were enabled to be transported and covered and with a more dense paste. While the mini-flow diameters increased with BFS replacements, they decreased with calcite additions.

\section{References}

Akgüngör, A., Sevim, Ö., Kalkan, İ., Demir, İ., Restrained Shrinkage Cracking of Self-Consolidating Concrete Roads. Science and Engineering of Composite Materials, 25(5), 1021-1030, 2018.

Anjuna, S., Nivin, P. (2016). Influence of metakaolin and silica fume on rheologıcal and mechanical properties of self-compacting concrete. International Academy of Science, Engineering and Technology, 5(6), 43-50.

Bombled, J. P. (1974). Rheologie des mortiers et des betons fraıs-etude de la pate interstitielle e cıment. Cıments Betons Platres Chaux, (688).

Boukhelkhal, D., Boukendakdji, O., Kenai, S., \& Bachene, S. (2015, May). Effect of mineral admixture type on stability and rheological properties of self-compacting concrete. In Rencontres Universitaires de Génie Civil.

Caufin, B., \& Papo, A. (1984). Rheological behaviour of cement pastes. ZKG International Cement-Lime-Gypsum, Edition B, 37(12), 656-661.

Concha, Nolan C., \& Melito A. Baccay. (2020). Effects of Mineral and Chemical Admixtures on the Rheological Properties of Self Compacting Concrete. International Journal of Geomate 18(66), 24-29.

Demir, I., Güzelkücük, S., Sevim, Ö. (2018a). Effects of sulfate on cement mortar with hybrid pozzolan substitution. Engineering Science and Technology, an International Journal, 21(3), 275-283.

Demir, İ., Sevim, Ö. (2017). Effect of sulfate on cement mortars containing Li2SO4, LiNO3, Li2CO3 and LiBr. Construction and Building Materials, 156, 46-55.

Demir, i., Sevim, Ö., Kalkan, İ. (2018b). Microstructural properties of lithium-added cement mortars subjected to alkali-silica reactions. Sādhanā, $43(7), 1-10$.

Demir, I., Sevim, Ö., Tekin, E. (2018c). The effects of shrinkage-reducing admixtures used in self-compacting concrete on its strength and durability. Construction and building materials, 172, 153-165.

Demir, I., Sivrikaya, B., Sevim, O., Baran, M. (2020). A study on ASR mitigation by optimized particle size distribution. Construction and Building Materials, 261, 120492.

EFNARC (2005). European Guidelines for Self-Compacting Concrete, Specification and Production and Use. Recommendation of European Federation of Producers and Contractors of Specialist Products for Structures. Norfolk, UK.

Feys, D., Verhoeven, R., \& De Schutter, G. (2007a). Evaluation of time independent rheological models applicable to fresh self-compacting concrete. Applied rheology, 17(5), 56244-1.

Feys, D., Verhoeven, R., \& De Schutter, G. (2007b). Steady-state rheological properties of fresh Self Compacting Concrete and their evolution in time. In Annual Transactions the Nordic Rheology Society-Nordic Rheology Conference, 15, (pp. 35-41). 
Feys, D., Verhoeven, R., \& De Schutter, G. (2008). Fresh self compacting concrete, a shear thickening material. Cement and Concrete Research, 38(7), 920-929.

Gökçe, M. (2013). Investigation of the interaction of paste phase with chemical admixtures in self-consolidating concrete. Ph.D. Thesis, Gazi University Graduate School of Natural and Applied Sciences. pp. 2.

Gökçe, M, Levent K.Y. \& Çankayalı A. (2010). Investigating the use chemical additives in buildings in terms of sustainability. International Sustainable Buildings Symposium, Ankara. pp. 94-97.

Gökçe, M. (2020). Determining the physical properties of polymer in different admixtures used for self-compacting cement paste by ESEM. Micron, 139, 102953. https://doi.org/10.1016/j.micron.2020.102953.

Gowda, M.R., Naveen, K.S.M., \& Laxmisagar, H.K. (2020). Development of Self Compacting Concrete using Silica Fume. International Journal for Scientific Research and Development, 4(11), 36-38.

Guzelkucuk, S., Demir, İ., Sevim, O., \& Kalkan, I. (2020). Mechanical properties and microstructure of cement multicomponent systems containing pozzolan materials under sulfate attack, Cement Wapno Beton, 25(2), 137-153.

Hočevar, A., Kavčič, F., \& Bokan-Bosiljkov, V. (2013). Rheological parameters of fresh concrete - Comparison of rheometers. Gradjevinar, 65(2), 99109.

Khayat, K. H., \& Yahia, A. (1997). Effect of welan gum-high-range water reducer combinations on rheology of cement grout. Materials Journal, 94(5), 365-372.

Kordts, S., \& Breit, W. (2003). Controlling the workability properties of self-compacting concrete used as ready-mixed concrete. 3rd Int. Symposium on Self-Compacting Concrete, Reykjavik, Iceland, pp. 17-20.

Ling, G., Shui, Z., Sun, T., Gao, X., Wang, Y., \& Sun, Y. (2018). Rheological behavior and microstructure characteristics of SCC incorporating metakaolin and silica fume. Materials, 11(12), 2576

Mohammed, B. S., Awang, A. B., San Wong, S., \& Nhavene, C. P. (2016). Properties of nano silica modified rubbercrete. Journal of Cleaner Production, 119, 66-75.

Özkul, H., \& Sağlam, A.R. (2002). Effect of super plasticizer and mineral admixtures on rheological properties of concrete. TUBiTAK Project No: İntag655. pp. 169-170.

Petit, J. Y., Wirquin, E., Vanhove, Y., \& Khayat, K. (2007). Yield stress and viscosity equations for mortars and self-consolidating concrete. Cement and concrete research, 37(5), 655-670.

Schwartzentruber, L. A., Le Roy, R., \& Cordin, J. (2006). Rheological behaviour of fresh cement pastes formulated from a Self-Compacting Concrete (SCC). Cement and Concrete Research, 36(7), 1203-1213.

Sevim, O., \& Sengul, C.G. (2021). Comparison of the Influence of Silica-rich Supplementary Cementitious Materials on Cement Mortar Composites: Mechanical and Microstructural Assessment. Silicon, 2021, 1-16. https://doi.org/10.1007/s12633-021-01013-7

Souza, S.R., Barcelos, J.H., \& Santos, W.J. (2018). Passing Ability Testing for Self-Compacting Concrete. International Journal of Science and Engineering Investigations, $7(78), 70-74$

Türkmen, ì. (2003). Influence of different curing conditions on the physical and mechanical properties of concretes with admixtures of silica fume and blast furnace slag. Materials Letters, 57(29), 4560-4569.

TS EN 197-1: Cement - Part 1 (2012). Composition, specification and conformity criteria for common cements. Turkish Standards Institution, Ankara.

TS EN 12350-8 (2019). Testing fresh concrete - Part 8: Self-compacting concrete - Slump-flow test. Turkish Standards Institution, Ankara.

TS EN 206:2013+A1. (2017). Concrete- Specification, performance, production and conformity. Turkish Standards Institution, Ankara.

Vanjare, M. B., \& Mahure, S. H. (2012). Experimental investigation on self compacting concrete using glass powder. International Journal of Engineering Research and Applications (IJERA), 2(3), 1488-1492.

Yılmaz, R. (2007). Flow and modeling of viscous materials. Master Thesis, Yıldız Technical University, Institute of Science and Technology, İstanbul. pp.154-155. 